\title{
O JUDICIÁRIO CONTEMPORÂNEO E O DEVER DE FUNDAMENTAÇÃO NO NOVO CÓDIGO DE PROCESSO CIVIL: AINDA NO ESTEIO TÓPICO DE THEODOR VIEHWEG
}

\section{CONTEMPORARY JUDICIARY AND THE DUTY TO STATE REASONS IN THE NEW CIVIL PROCEDURE CODE: STILL IN THE TOPIC MAINSTAY OF THEODOR VIEHWEG}

Márcio Roberto Torres ${ }^{1}$

\section{RESUMO}

O presente artigo tem por objetivo demonstrar a contribuição da teoria de Theodor Viehweg para o raciocínio jurídico. Combatendo o puro raciocínio lógico, a teoria tópica pretende racionar através de problemas. Com o Novo Código de Processo Civil Brasileiro, o dever de fundamentação é desenvolvido em flagrante relação com o conflito, sendo papel do juiz não descuidar da vinculação entre a norma e os fatos como forma de legitimação das decisões.

Palavras-chave: Teoria Tópica; Viehweg; Dever de Fundamentação; Hermenêutica; Justificação Externa.

\begin{abstract}
This paper aims to demonstrate the contribution of the Theodor Viehweg's theory for legal reasoning. Fighting pure logical reasoning, topic theory wants to ration through problems. With the New Brazilian Civil Procedure Code, the obligation to state reasons is developed in flagrant connection with the conflict, and role of the judge is not to overlook the link between the norm and the facts as a way of legitimizing the decisions.
\end{abstract}

Keywords: Topic Theory; Viehweg; Obligation to State Reasons; Hermeneutics; External Justification.

\footnotetext{
${ }^{1}$ Mestrando em Direito pela Universidade Federal de Alagoas - UFAL. Alagoas (Brasil). Pós-graduado (lato sensu) em Direito Processual. Professor do Centro Universitário CESMAC. Procurador do Município de Maceió/AL. Advogado. E-mail: torres_mr@hotmail.com
} 


\section{INTRODUÇÃO}

Aplicar o Direito já foi algo extremamente vinculado ao ideal positivista da ciência, imbuído de uma suposta razão e de empirismo e previsibilidade, como forma de responder ao absolutismo de outrora, bastando ver a síntese de Rodolfo Luis Vigo (2010, p. 37).

Se, no tempo do positivismo legalista, o silogismo dominava a mentalidade do jurista da época, tal fato refletia uma preocupação restrita às justificações internas das decisões. É acertada a correlação feita por Adeodato (2012, p. 165-166) entre tal escola positivista e o repúdio às influências externas e não empíricas. $\mathrm{O}$ dedutivismo respondia aos anseios sociais por segurança jurídica, e até o código napoleônico, que havia sido idealizado para compatibilizar-se com o direito natural, passou a representar, contraditoriamente, o exegetismo (BOBBIO, 2006, p. 73). Oportuna a conclusão de Pedro Henrique Nogueira (2016, p. 188-189):

Durante o século XIX, após o surgimento das primeiras codificações europeias, sobretudo com o advento do Código Civil da França de 1804, predominou a estipulação de pautas normativas de conduta em termos gerais e abstratos. Na própria ideologia da codificação, estavam presentes a concepção de exatidão (o código dispensaria até mesmo a interpretação para ser aplicado) e a de completude (o código seria capaz de regular todos os fatos da vida), garantidores da segurança e previsibilidade em favor do indivíduo. [...] O juiz era submisso à lei e a atividade judicial de aplicação do direito se resumiria a uma operação de silogismo; [...] A partir do século XX, as concepções de interpretação e de aplicação do direito sofreram profundas transformações. Hoje, a atividade judicial não é mais vista como operação de mera aplicação de Direito preexistente. Interessa em maior medida à hermenêutica jurídica saber o que é e qual o papel da interpretação, em lugar de se buscar um método presumivelmente capaz de possibilitar uma interpretação como correta.

As experiências funestas que brotaram do nazismo, fruto oriundo de um Estado de Direito, serviram de argumento para uma reaproximação entre a ordem jurídica e as considerações morais. A partir daí, mais do que uma mera justificação interna, conquistou lugar a justificação externa das decisões jurídicas, reconhecendo-se o papel corretivo da moral, e dando lugar às justificações externas das premissas (ATIENZA, 2014, p 32-33).

É fato, e disto ninguém duvida, que as evoluções não costumam, apesar de não se descartar a possibilidade, ocorrer de forma flamejante, mas são construtos de uma longa cadeia de estudos. Assim aconteceu e acontece com a argumentação jurídica. 
Um dos seus estudiosos, cujo contributo teórico até hoje marca implicitamente a aplicação da norma, foi Theodor Viehweg, que retomou a forma de raciocínio da antiguidade e do medievo, cuja importância havia sido relegada após o advento do cartesianismo. Mais do que uma aplicação meramente dedutiva, cumprindo com a figura da subsunção ou do silogismo, o operador jurídico utiliza um raciocínio pautado pelo problema com que se depara (BONAVIDES, 2015, p. 500-501). A noção de problema em Viehweg coincide com a usualmente empregada como hard case, ou seja, toda questão que aparentemente permite mais de uma resposta (VIEHWEG, 1979, p. 34).

Século XXI. Ultrapassados mais de 60 anos da obra de Viehweg, a República Federativa do Brasil festeja o advento de um novo Código de Processo Civil, que estabelece, dentre outros pontos, um fundamental dever de fundamentação judicial, em seu artigo 489, $\S 1^{\text {o } 2}$

Em tempos de neoconstitucionalismo, onde os hard cases envolvem a presença constante dos princípios, é incomensurável o papel jurisdicional. Normas principiológicas estabelecem fins, deixando-se os meios para a sua consecução à escolha do aplicador, que terá o ônus de fundamentar concretamente os caminhos tomados. Tratando-se de princípios constitucionais, em virtude de sua tessitura aberta e natureza finalística, existe uma gama de condutas aptas e legítimas para sua concretização, como expõe a doutrina moderna, representada por Ávila (2014, p. 102-103).

Debruçando-se sobre a obra de Robert Alexy, Lenio Streck (2016, p. 51) assevera que, "[...] ao contrário do que entendia Hart, para Alexy a dimensão de abertura era a porta de entrada, no interior do discurso jurídico, para elementos morais ou questões de justiça presentes naquilo que ele denomina discurso prático geral”.

\footnotetext{
2 O diploma trouxe um elenco de situações em que não se considera fundamentado o decisório. Segundo prescreve, não se considera fundamentada qualquer decisão judicial, seja ela interlocutória, sentença ou acórdão, que:

I - se limitar à indicação, à reprodução ou à paráfrase de ato normativo, sem explicar sua relação com a causa ou a questão decidida;

II - empregar conceitos jurídicos indeterminados, sem explicar o motivo concreto de sua incidência no caso;

III - invocar motivos que se prestariam a justificar qualquer outra decisão;

IV - não enfrentar todos os argumentos deduzidos no processo capazes de, em tese, infirmar a conclusão adotada pelo julgador;

V - se limitar a invocar precedente ou enunciado de súmula, sem identificar seus fundamentos determinantes nem demonstrar que o caso sob julgamento se ajusta àqueles fundamentos;

VI - deixar de seguir enunciado de súmula, jurisprudência ou precedente invocado pela parte, sem demonstrar a existência de distinção no caso em julgamento ou a superação do entendimento.
} 
Ainda, Alexy (2013, p. 19-20) reconhece a existência de casos em que a norma aplicável concretamente parece não derivar das normas jurídicas que se supõem vigentes. Nestes casos, fundamentar especificamente é essencial. Segundo explicita,

Em um grande número de casos, a decisão jurídica que põe fim a uma disputa judicial, expressa em um enunciado normativo singular, não se segue logicamente das formulações das normas jurídicas que se supõem vigentes, juntamente com os enunciados empíricos que se devam reconhecer como verdadeiros ou provados. Para tanto, há no mínimo quatro motivos: (1) imprecisão da linguagem do Direito, (2) a possibilidade de conflitos entre as normas, (3) a possibilidade de haver casos que requeiram uma regulamentação jurídica, uma vez que não cabem em nenhuma norma válida existente, bem como (4) a possibilidade, em casos especiais, de uma decisão que contraria a literalidade da norma.

Incumbe às partes e ao magistrado, em uma contenda, demonstrar a conexão entre os elementos normativos e os fáticos, entre o texto e o caso concreto. Eis a sombra tópicoproblemática de Viehweg.

A abordagem que se busca, então, é aproximar a academia e a prática judicial (POSNER, 2009, p. 417). A falência de um papel argumentativo dos sujeitos processuais implicará na perda de legitimidade do processo judicial.

Analisando a sobrevivência do pensamento tópico-problemático reinaugurado por Theodor Viehweg, o trabalho busca demonstrar a sua adoção pelo legislador brasileiro, e sua necessária utilização pelo aplicador jurídico.

Para o estudo, a metodologia utilizada será, predominantemente, a análise doutrinária e sua comparação com os textos legais e com pequeno repertório jurisprudencial.

\section{A FUNDAMENTAÇÃO COMO FATOR LEGITIMADOR DO JUDICIÁRIO}

Passando pelos estágios do pensamento jurídico, pode-se perceber uma verdadeira oscilação entre subjetivismos e objetivismos. No Crátilo, de Platão, já se encontra uma verdadeira crítica da linguagem, uma discussão entre o naturalismo e o convencionalismo. Como demonstra Streck (2014, p. 177), 
são contrapostas duas teses / posições sobre a semântica: o naturalismo, pelo qual cada coisa tem nome por natureza (o logos está na physis), tese defendida no diálogo por Crátilo, e o convencionalismo, posição sofística defendida por Hermógenes, pelo qual a ligação do nome com as coisas é absolutamente arbitrária e convencional, é dizer, não há qualquer ligação das palavras com as coisas.

Posteriormente, a doutrina centra em Aristóteles a busca pela essência das coisas. Segundo o escólio, “[...] é a essência ou substância (ousía), enquanto unidade objetiva, que fundamentará a significação das palavras” (VEIRA LUIZ, 2013, p. 29).

A essência das coisas, a par de sua relevância, pode ensejar interpretações pautadas em um mero raciocínio lógico, ignorando o papel do intérprete e do próprio problema.

Tal discussão evolui, sendo que com o surgimento da filosofia da consciência e o sujeito da modernidade, pode-se centrar uma verdadeira base no subjetivismo interpretativo. É que "[...] a filosofia transcendental kantiana representa, portanto, o ponto máximo da subjetividade" (VIEIRA LUIZ, 2013, p. 29).

Um exemplo de subjetivismo pode ser encontrado em Kelsen (1998, p. 390), e sua ideia de moldura, dentro da qual há diversas interpretações possíveis.

Igualmente, Hart (1994) defende que, nos casos difíceis, o juiz, apesar de submetido a diversos constrangimentos, tem uma missão “[...] inevitável, porém intersticial, de criação de direito, e que tanto diz respeito ao direito, muitos casos podiam ser decididos num sentido ou noutro".

Nem tanto a terra (objetivismo), nem tanto ao mar (subjetivismo). Se o papel do intérprete não pode ser descartado, tampouco a relevância dos textos pode ser negligenciada. E é esta uma das mais tortuosas tarefas do operador jurídico, encontrar a sinergia da norma com o caso.

Em tempos de pós-positivismo, cada vez mais se busca uma efetividade constitucional, ponto que modifica a forma de interpretar a Constituição. Barroso (2014, p. 344), tentando negar o subjetivismo, sintetiza o momento da seguinte maneira:

O pós-positivismo identifica um conjunto de idéias difusas que ultrapassam o legalismo estrito do positivismo normativista, sem recorrer às categorias da 
razão subjetiva do jusnaturalismo. Sua marca é a ascensão dos valores, o reconhecimento da normatividade dos princípios e a essencialidade dos direitos fundamentais. Com ele, a discussão ética volta do Direito. O pluralismo político e jurídico, a nova hermenêutica e a ponderação de interesses são componentes dessa reelaboração teórica, filosófica e pratica que fez a travessia de um milênio para o outro. [...] Foi fruto de duas mudanças de paradigma: a) a busca da efetividade das normas constitucionais, fundada na premissa da força normativa da Constituição; b) o desenvolvimento de uma dogmática da interpretação constitucional, baseada em novos métodos hermenêuticos e na sistematização de princípios específicos de interpretação constitucional.

O papel de fundamentação das decisões judiciais é algo de que não se pode descuidar, não apenas por representar a figura da racionalidade, mas por ser fator de legitimação e controle social. Segundo Luño (2012, p. 64),

A identificação do conceito geral do direito com as decisões judiciais enfrenta um importante dilema jurídico e político. Trata-se da exigência postulada pelo racionalismo jurídico, que será o germe do movimento constitucionalista incentivador do Estado de direito, de estabelecer-se o princípio da divisão de poderes.

Há autores que, preocupados, defendem até mesmo a retirada de questões que envolvam grandes desacordos da competência do Poder Judiciário. O neozelandês Waldron (2006, p. 1406) advoga que se deve criar uma série de mecanismos que dirimam eventuais desacordos sobre direitos, que seriam o maior problema das sociedades razoavelmente democráticas:

\begin{abstract}
Desacordo sobre os direitos não é razoável, e as pessoas podem discordar sobre direitos enquanto ainda os levam a sério. Nestas circunstâncias, elas precisam adotar procedimentos para revolvendo suas discordâncias que respeitem as vozes e opiniões das pessoas cujos direitos estão em jogo nestas discordâncias e tratá-las como iguais no processo. [...] Procedimentos legislativos ordinários podem fazer isso, eu tenho defendido, e uma camada adicional de revisão final pelos tribunais acrescenta pouco ao processo, exceto uma forma bastante insultuosa de privação de direitos e uma ofuscação legalista das questões morais (Tradução Nossa). ${ }^{3}$
\end{abstract}

\footnotetext{
${ }^{3}$ No original: "Disagreement about rights is not unreasonable, and people can disagree about rights while still taking rights seriously. In these circumstances, they need to adopt procedures for revolving their disagreements that respect the voices and opinions of the persons whose rights are at stake in these disagreements and treat them as equals in the process. [...] Ordinary legislative procedures can do this, I have argued, and an additional
} 
E é na certeza de que não se pode subtrair da apreciação do Estado-Juiz, ao menos no presente estágio de desenvolvimento constitucional brasileiro, as matérias polêmicas, que se evidencia o papel do dever de fundamentação judicial.

Discorrendo sobre o papel do judiciário, Barroso (2012, p. 309) ressalta a polêmica acerca da sua atuação. Segundo leciona, “[...] ativistas e não ativistas, todavia, não contestam o que se denomina supremacia judicial: o reconhecimento de que deve caber ao judiciário a última palavra acerca da interpretação da Constituição e das leis”. Traçando um paralelo com os demais Poderes, e lembrando a corrente do constitucionalismo popular, passa a defender o papel contramajoritário do Estado-Juiz:

Uma das grandes questões subjacentes à legitimação democrática do Poder Judiciário é a denominada dificuldade contramajoritária. [...] Onde estaria o fundamento para o Judiciário sobrepor sua vontade à dos agentes eleitos dos outros Poderes? A resposta já está amadurecida na teoria constitucional: na confluência de ideias que produzem o constitucionalismo democrático. [...] Aí está o segundo grande papel de uma Constituição: proteger valores e direitos fundamentais, mesmo que contra a vontade circunstancial de quem tem mais votos (BARROSO, 2014, p. 309).

Se ao Poder Judiciário Contemporâneo não se pode subtrair competência, maior é seu dever de fundamentação. O Estado-Juiz é terceiro equidistante das partes, e sua missão de resolver os conflitos de interesse deve ser levada a cabo da maneira mais transparente possível, aumentando progressivamente o seu grau de aceitabilidade.

Com esta conjuntura, assiste razão a Rodriguez (2013, p. 214), quando pontua que não há plausibilidade jurídica em um modelo de racionalidade jurisdicional que não leve em conta as características reais da ordem jurídica. Pensar que textos fechados garantem segurança jurídica é equivocado. O problema da segurança não se resolve só com leis, mas levando-se em conta o processo de aplicação e a fundamentação das decisões judiciais. Devese sair de um paradigma textualista para um paradigma argumentativo.

\section{A FUNDAMENTAÇÃO NO NOVO CPC - AINDA NA TRILHA DE VIEHWEG}

layer of final review by courts adds little to the process except a rather insulting form of disenfranchisement and a legalistic obfuscation of the moral issues [...]." 
A teoria tópica de Theodor Viehweg continua a ter amparo nos dias atuais. Sem perder de vista desenvolvimentos ulteriores no campo da argumentação jurídica, que demonstraram a importância de se partir do sistema, e não do problema, não se pode ignorar o papel embrionário desempenhado por sua obra Tópica e Jurisprudência. ${ }^{4}$

Encarada como uma forte crítica ao positivismo legalista e ao puro raciocínio lógicodedutivo, a obra de Viehweg resgata, após fazer um panorama histórico na antiguidade e na idade média, o raciocínio entimemático desenvolvido por Aristóteles (ÁVILA, 2005, p. 11).

Diferenciando os raciocínios apodíticos (campo da verdade) dos raciocínios dialéticos (campo do provável ou verossímil), Viehweg demonstra que estes partem de proposições conforme opiniões aceitas, acreditadas e verossímeis, que devem contar com aceitação (VIEHWEG, 1979, p. 25). ${ }^{5}$

Segundo se depreende das lições tópicas, sempre que o aplicador se depara com um problema, inicia-se um jogo de suscitações entre os interessados em resolvê-lo, que acabam argumentando através de topoi, pontos de vistas utilizáveis e aceitáveis em toda parte, que se empregam a favor ou contra o que é conforme a opinião aceita e podem conduzir à verdade. São pontos de partida para a série argumentativa (VIEHWEG, 1979, p. 33-35).

A título exemplificativo, se existe uma simples discussão acerca de qual marca de cafeteira deve ser comprada por uma turma, e esta chega ao consenso de que valeria a decisão da maioria, estar-se-ia aplicando o topos da maioria. Os topoi são fruto de consenso, e disto não se pode esquecer.

Sem a pretensão de constituir um método, Theodor Viehweg elabora um modo de pensar por problemas. Do ponto de vista do objeto, é uma técnica de pensamento problemático, do ponto de vista do instrumental, faz uso da noção de topoi, e do ponto de vista da atividade, é uma busca e exame de premissas (ATIENZA, 2014, p. 43). Se é através do problema concreto que a solução é encontrada, não há o puro raciocínio lógico-dedutivo. Claro, depois de encontradas as premissas e soluções, estas devem ser apresentadas sob a forma silogística, transmitindo-se a ideia de racionalidade. Assim, resgatando a visão de Cícero, há diferença entre a invenção (ars inveniendi), onde se encontram as premissas, e a

\footnotetext{
${ }^{4}$ Lançada na década de 50, a obra faz menção à palavra jurisprudência no sentido de ciência do direito.

${ }^{5}$ Endoxa - proposições que parecem verdadeiras a todos ou a maior parte ou aos sábios.
} 
formação do juízo (ars iudicandi), onde se apresentam as premissas sob uma forma lógica. A tópica passa a ser encarada como uma etapa pré-lógica capaz de superar as aporias, os problemas iniludíveis (VIEHWEG, 1979, p. 39-40).

Realizando uma digressão pelo Ius Civile e pelo Mos Italicus, Viehweg demonstra que até no medievo a forma de pensar era feita por meio de problemas, sem longas cadeias dedutivas. Posteriormente, tratando da civilística, chega a um conjunto de conclusões que interessam em tudo para o que se pretende demonstrar nesta oportunidade (VIEHWEG, 1979, p. 19-89).

Segundo Viehweg (1979, p. 89), a estrutura total da jurisprudência somente pode ser determinada a partir do problema. Além disto, as partes integrantes da jurisprudência, seus conceitos e proposições têm de ficar ligados de um modo específico ao problema e só podem ser compreendidos a partir dele. Por fim, esclarece que os conceitos e proposições da jurisprudência só podem ser utilizados em uma implicação que conserve sua vinculação com o problema.

O raciocínio por meio de problemas é capaz de esclarecer a ausência de absolutismo de regras ou princípios em determinadas situações, o que hoje se convencionou chamar de derrotabilidade.

Tratando da efetivação dos direitos sociais pelo Judiciário, Krell (2012, p. 147) reconhece a construção aqui realizada e chega à interessante e inarredável conclusão de que “a questão decisiva é a configuração concreta dos textos legais a serem aplicados ao caso: se houver uso de conceitos vagos ou se a norma tiver caráter principiológico, normalmente restará ao intérprete um espaço maior de valoração dos fatos”.

Contemporaneamente, a ausência de critérios claros de decisão ensejou uma série de estudos doutrinários, cabendo mencionar, por todos, o trabalho de Lorenzetti, que organiza a sua obra partindo das perspectivas de ação do magistrado, que denomina de paradigmas de compreensão. Para o autor,

O vocábulo paradigma tem muitos sentidos diferentes. No nosso caso, fazemos referência aos modelos decisórios que têm um status anterior à regra e condicionam as decisões. Quem se baseia apenas em paradigmas dá prevalência ao contexto em detrimento da norma, mediante um procedimento que consiste em subsumir um termo legal em um contexto que 
lhe empresta sentido, e que não é o ordenamento, mas o modelo de decisão adotado de antemão pelo intérprete (LORENZETTI, 2009, p. 36).

Tentando controlar o resultado da interpretação, evitando a subjetividade do intérprete, Lorenzetti organiza uma metodologia, que parte, segundo síntese de Vieira Luiz (2013, p. 137), da "[...] dedução das regras válidas, controlando-se o seu resultado (com os critérios de consistência, coerência e consequencialista); após, se não encontrada a solução, deve-se aplicar a ponderação; por fim, proceder-se-á a explicação e harmonização dos paradigmas presentes".

Nos Estados Unidos da América, há uma clara visão do caráter político das decisões judiciais por muitos autores, inclusive se analisando as diferentes posturas de juízes de indicação republicana ou democrata, o que reforça o conceito de paradigma acima exposto, e o conceito de subjetivismo. Basta ver as lições de Sunstein, Schkade, Ellman e Sawicki (2006, p. 129):

descobrimos que em muitas áreas há uma diferença significativa entre os padrões de votação de indicados Republicanos daqueles de indicados Democratas. [...] A um grau substancial, as tendências ideológicas das cortes de apelação estão correlacionadas com os percentuais de indicados por presidentes Republicanos e Democratas. E dentro dos tribunais, mudanças ideológicas ao longo do tempo têm muito a ver com as mesmas percentagens. Nada disso nega os efeitos disciplinadores do direito. Em algumas áreas, as diferenças ideológicas são inexistentes. Na maioria das áreas, elas não são enormes. Mas a presença do partido e do painel de efeitos é inegável. (Tradução Nossa). ${ }^{6}$

Até na teoria de Lorenzetti, há a necessidade de se racionar levando-se em consideração o problema.

A menção ao caso concreto e aos topoi consagrados no cotidiano jurídico é corriqueira, bastando ver as seguintes ementas (sem grifos nos originais):

PROCESSO CIVIL E ADMINISTRATIVO. APELAÇÃO CÍVEL. NULIDADE SENTENÇA. VIOLAÇÃO AO DEVIDO PROCESSO

\footnotetext{
${ }^{6}$ No original: "[...] we have found that in many areas, there is a significant difference between the voting patterns of Republican appointees and those of Democratic appointees. [...] to a substantial degree, the ideological tendencies of courts of appeals are correlated with the percentages of appointees by Republican and Democratic presidents. And within the courts, ideological shifts over time have a great deal to do with the same percentages. None of this denies the disciplining effects of law. In some areas, the ideological differences are nonexistent. In most areas, they are not huge. But the presence of party and panel effects is undeniable".
} 
LEGAL. ATO JURÍDICO PERFEITO. PROCEDIMENTO LICITATÓRIO. COMPETITIVIDADE. REGRAS EDITALÍCIAS. RECURSO DESPROVIDO. 1. A adequada qualificação jurídica dos fatos descritos pelas partes é incumbência do juiz, que poderá fazê-lo de ofício em atenção à teoria da substanciação (substantiierungstheorie). Aplicação dos topoi jurídicos iura novit curia e narra mihi facto dabo tibi ius. Eventuais qualificacõos jurídicas constantes na peticão inicial são meras propostas de subsunção a determinado conjunto de regras e não vinculam a atividade cognitiva do magistrado. 2 . A anulação do procedimento licitatório e, consequientemente, do contrato administrativo, não exige prévio processo administrativo com a garantia do contraditório e da ampla defesa. Precedentes do STJ. 3. O particular não pode exigir a manutenção do ato nulo ou o respeito a seus efeitos, eis que inexiste direito adquirido em face da Administração nos casos de nulidade. 4. A possibilidade de escolha da proposta mais vantajosa à Administração Pública deve ser assegurada mediante a participação e a competitividade do certame, sob pena de inegável prejuízo ao interesse público. 5. A Administração Pública tem o dever de invalidar os seus próprios atos caso inobservados os critérios editalícios para a escolha da proposta mais vantajosa. 6. Recurso desprovido. (TJ-ES - AC: 6070010027 ES 6070010027, Relator: SAMUEL MEIRA BRASIL JUNIOR, Data de Julgamento: 22/07/2008, SEGUNDA CÂMARA CÍVEL, Data de Publicação: 18/08/2008).

HABEAS DATA - NATUREZA JURÍDICA - DELEGADO DE POLÍCIA FOTO EM ÁLBUM DE SUSPEITOS DE CRIMES - REQUERIMENTO DE INFORMAÇÕES - RECUSA POR OMISSÃO. Segundo o art. $8^{\circ}, \S 1^{\circ}$, inciso I, da Lei n. 9.053/97, é requisito da ação de habeas data a inadmissão por parte da autoridade coatora em prestar as informações solicitadas. In casu, o togado a quo extinguiu o processo sem julgamento do mérito, por falta de interesse de agir, considerando que o requerimento administrativo anexado não constituiu prova suficiente à recusa, pois não fora protocolado. NORMA CONSTITUCIONAL - INTERPRETACÃO TÓPICA CONCRETIZACÃ̃. No processo de concretizacão da norma, o juiz deve partir do problema, considerando também as normas, mas com o desprendimento suficiente para atingir o objetivo principal que é a efetividade do direito que se busca garantir. Partindo de pontos-de-vista varíáveis, ou seja, dos topoi, segundo os quais se ponderam os prós e os contras das opiniões para a conducão do que é verdadeiro, busca-se o resultado mais justo para o litígio. EXTINÇÃO SEM ANÁLISE DO MÉRITO - PROCESSO EM CONDIÇÕES DE JULGAMENTO. Segundo o art. 515, $\S 3^{\circ}$, do CPC, é permitido ao tribunal ad quem o julgamento imediato da lide, quando a causa versar sobre questão exclusivamente de direito. (TJ-SC - AC: 64802 SC 2004.006480-2, Relator: Volnei Carlin, Data de Julgamento: 21/10/2004, Primeira Câmara de Direito Público, Data de Publicação: Apelação cível n. 04.006480-2, de Joinville).

O dever de fundamentação previsto no Novo Código de Processo Civil é totalmente vinculado ao caso concreto, bastando ver a dicção do artigo 489, $\S 1^{\circ}$, do Código de Processo Civil, que prescreve não se considerar fundamentada a decisão judicial quando: I - se limitar à 
indicação, à reprodução ou à paráfrase de ato normativo, sem explicar sua relação com a causa ou a questão decidida; II - empregar conceitos jurídicos indeterminados, sem explicar o motivo concreto de sua incidência no caso; III - invocar motivos que se prestariam a justificar qualquer outra decisão; IV - não enfrentar todos os argumentos deduzidos no processo capazes de, em tese, infirmar a conclusão adotada pelo julgador; V - se limitar a invocar precedente ou enunciado de súmula, sem identificar seus fundamentos determinantes nem demonstrar que o caso sob julgamento se ajusta àqueles fundamentos; VI - deixar de seguir enunciado de súmula, jurisprudência ou precedente invocado pela parte, sem demonstrar a existência de distinção no caso em julgamento ou a superação do entendimento.

Ao fundamentar, o magistrado reconduz as partes e a sociedade pelo caminho que percorreu (ao menos do ponto de vista da justificação interna) para chegar à decisão jurisdicional. Segundo Marinoni (2016, p. 205-206),

$\mathrm{Na}$ concepção tradicional do direito processual civil de civil law, a fundamentação é relacionada com a necessidade de o juiz apresentar as razões que lhe permitiram chegar à conclusão, isto é, à decisão. Em vista da sua própria estrutura, a decisão tem de ter as suas razoes ou os seus fundamentos. [...] Isso permite o controle da atividade do juiz pelas partes ou por qualquer um do povo, já que a sentença deve ser o resultado de raciocínio lógico que assenta no relatório, na fundamentação e no dispositivo.

A doutrina, já em atenção ao dever de vinculação da norma ao caso, leciona que o dispositivo preconiza as "hipóteses em que a decisão [...] não é considerada fundamentada, exigindo do julgador que peculiarize o caso julgado e a respectiva fundamentação diante das especifidades que lhe são apresentadas" (BUENO, 2015, p. 325). A menção ao caso concreto, como se pode depreender, é corriqueira no dispositivo, o que faz ressurgir a questão problemática tão colocada por Viehweg.

Se não se pode meramente reproduzir ato normativo sem explicar sua relação com a causa ou questão decidida, há a necessidade de um verdadeiro raciocínio tópico. É este, como já se disse acima, o verdadeiro desafio do operador, vincular a norma ao caso. 
Igualmente, empregar conceitos jurídicos indeterminados sem a explicação do motivo concreto da incidência no caso é combatido por não permitir o chamado jogo de suscitações de que se tratou.

Invocar motivos que se prestariam a justificar qualquer outra decisão, por sua vez, representa aplicar norma dissociada da realidade fática, o que é contrário ao pensamento tópico-problemático.

Não enfrentar todos os argumentos deduzidos no processo capazes de, em tese, infirmar a conclusão adotada pelo julgador representa negar a argumentação veiculada pelas partes, em flagrante negativa ao caráter dialógico do processo e aos topoi articulados.

Limitar-se a invocar precedente ou enunciado de súmula, sem identificar seus fundamentos determinantes nem demonstrar que o caso sob julgamento se ajusta àqueles fundamentos é, novamente, dissociar-se da realidade fática.

Deixar de seguir enunciado de súmula, jurisprudência ou precedente invocado pela parte, sem demonstrar a existência de distinção no caso em julgamento ou a superação do entendimento é ignorar a endoxa levantada pelos litigantes.

Exemplos de topoi levantados no Direito podem se retratados no estudo de Krell (2016, p. 264), que retratando o pensamento de Esser, lista as noções de "bem-estar geral, proteção da boa-fé, natureza da coisa, princípio da prioridade, vedação da fraude à lei, dignidade humana, liberdade, igualdade, solidariedade".

Chegando ao extremo, os comentadores do Novo Código de Processo Civil são categóricos em afirmar que "não se admite a prolação de decisões falsamente motivadas ou com 'simulacro de fundamentação'. É o que se dá nos casos arrolados no § $1^{\circ}$ do artigo 489, o qual enumera uma série de casos de falsa fundamentação" (CÂMARA, 2016, p.16).

O espírito de que se encontra imbuído o novel diploma processual é tamanho que o Fórum Permanente de Processualistas possui entendimento no sentido de que as hipóteses acima comentadas são meramente exemplificativas. ${ }^{7}$

Não se pode, então, desprezar o caso concreto. Ainda se permanece no esteio tópico de Viehweg.

\footnotetext{
${ }^{7}$ O Fórum Permanente de Processualistas possui uma série de enunciados referentes ao Novo Código de Processo Civil. O enunciado em questão é o de número 303, que dispõe que as hipóteses descritas no $\S 1^{\circ}$ do artigo 489 são exemplificativas.
} 
É importante frisar que o raciocínio problemático é compatível com a ideia de sistema, estabelecendo com ela uma estreita relação. Regras, princípios, figuras dogmáticas, decisões judiciais, consequências sociais e políticas da decisão, tudo é levado em conta do processo decisório como demonstram Olga Krell e Andreas Krell (2016, p. 261-266).

Os pensamentos tópico e sistemático não são opostos, mas se complementam mutuamente, interpenetram-se. A tópica auxilia a determinação sistemática da resolução. Também, assiste à concretização de cláusulas gerais, já que o pensamento sistemático dela não consegue livrar-se (CANARIS, 2002, p. 273-277).

Até mesmo Hayek, (1985, p. 122-124) que defende o Direito como uma ordem evolutiva, realçando o papel da tradição e do consenso, aponta a importância da correspondência de normas com os fatos, com essa ordem prática, sendo impossível dissociar Direito e realidade.

Taruffo (2014, p. 641-642), um dos maiores defensores da função epistêmica do processo, entende que este só será capaz de alcançar a verdade, proporcionando decisões justas, se houver uma averiguação veraz dos fatos relevantes do caso:

Uma decisão é justa se se funda sobre uma averiguação veraz dos fatos relevantes. Como já indiquei, a veracidade da averiguação dos fatos não é a única condição de justiça da decisão (posto que não menos importante é a correta aplicação das normas que são assumidas como critério de juízo), mas, de qualquer modo, vale a pena destacar que se trata de uma condição necessária, baseada na tradicional e difundida constatação de que nenhuma decisão pode ser considerada justa e legítima caso seja fundada 'sobre fatos errados', ou seja, sobre uma reconstrução errônea da fattispecie concreta que é objeto de decisão. Esta tese encontra uma recente e muito significativa confirmação na obra já lembrada de Ferrajoli, o qual coloca em evidência como o correto exercício da função de garantia que é desenvolvida pela jurisdição encontra seu fundamento em uma atividade cognitiva que concerne ainda à averiguação dos fatos sobre os quais se funda a aplicação da lei.

Como se pode observar, o caso concreto, o problema, o raciocínio a ele direcionado, são dados inarredáveis.

\section{CONCLUSÕES}


Após as conclusões encimadas, pode-se perceber que a tópica encontra assento em diversos dispositivos que tratam da fundamentação no Novo Código de Processo Civil.

Diferentemente do que se poderia pensar, o raciocínio através de problemas é relevante e permite ao operador do direito uma análise que confira maior grau de legitimidade às decisões jurídicas. A defesa de um raciocínio puramente lógico-dedutivo encontra obstáculo robusto na exigência de uma justificação externa, sendo que com a techne de pensamento problemático é que se pode conferir aceitabilidade ao processo.

Não é por menos que o próprio Viehweg $(1979$, p. 107) estabelecia como deveres das partes em um problema os de afirmação, fundamentação, defesa e esclarecimento, elucidando que quem fala tem de poder justificar sua fala.

Falar, contudo, em raciocínio tópico não implica excluir a relevância do sistema, que permanece numa relação clara de interdependência com o caso concreto. Dedução de conceitos legais e análise concreta se imbricam na aplicação do Direito.

Assim, continuam vivas, ao menos parcialmente, as construções teóricas desenvolvidas por Viehweg, que influenciaram diversas teorias posteriores e a própria essência de vários dispositivos do Código de Processo Civil vigente.

\section{REFERÊNCIAS}

ADEODATO, João Maurício. Ética e retórica: Para uma teoria da dogmática jurídica. 5. ed. São Paulo: Saraiva, 2012.

ALEXY, Robert. Teoria da argumentação jurídica: a teoria do discurso jurídico racional como teoria da fundamentação jurídica. 3. ed. Rio de Janeiro: Forense, 2013.

Teoria dos Direitos fundamentais. 3. ed. São Paulo: Malheiros, 2014.

ATIENZA, Manuel. As razões do Direito: Teoria da Argumentação Jurídica. $2^{a}$ ed. Rio de Janeiro: Forense Universitária, 2014.

ÁVILA, Humberto. Teoria dos princípios: da definição à aplicação dos princípios jurídicos. 15. ed. São Paulo: Malheiros, 2014.

ÁVILA, Luiz Augusto Lima de. Tópica e Teoria Constitucional do Direito: As Eternas Aporias e a Uberdade da Abdução. In: Revista Brasileira de Direito Constitucional - n. 7 - Jan/Jun 2006 - Vol. 2. 
BARROSO, Luís Roberto. Interpretação e aplicação da Constituição. 7. ed. São Paulo: Saraiva, 2014.

Curso de Direito constitucional contemporâneo: conceitos fundamentais e a construção do novo modelo. 3. ed. São Paulo: Saraiva, 2012.

BOBBIO, Norberto. O Positivismo jurídico: Lições de filosofia do direito. São Paulo: Ícone, 2006.

BONAVIDES, Paulo. Curso de Direito constitucional. 30ª ed. São Paulo: Malheiros, 2015.

BRASIL. Código de Processo Civil. Disponível em:

<http://www.planalto.gov.br/ccivil 03/ ato2015-2018/2015/lei/113105.htm>. Acesso em 14 set. de 2016.

BRASIL. Tribunal de Justiça do Espírito Santo. Processo civil e administrativo. Apelação cível. Nulidade sentença. Violação ao devido processo legal. Ato jurídico perfeito. Procedimento licitatório. Competitividade. Regras editalícias. Recurso desprovido. 1. A adequada qualificação jurídica dos fatos descritos pelas partes é incumbência do juiz, que poderá fazê-lo de ofício em atenção à teoria da substanciação (substantiierungstheorie). Aplicação dos topoi jurídicos iura novit curia e narra mihi facto dabo tibi ius. Eventuais qualificações jurídicas constantes na petição inicial são meras propostas de subsunção a determinado conjunto de regras e não vinculam a atividade cognitiva do magistrado. 2. A anulação do procedimento licitatório e, conseqüentemente, do contrato administrativo, não exige prévio processo administrativo com a garantia do contraditório e da ampla defesa. Precedentes do STJ. 3. O particular não pode exigir a manutenção do ato nulo ou o respeito a seus efeitos, eis que inexiste direito adquirido em face da Administração nos casos de nulidade. 4. A possibilidade de escolha da proposta mais vantajosa à Administração Pública deve ser assegurada mediante a participação e a competitividade do certame, sob pena de inegável prejuízo ao interesse público. 5. A Administração Pública tem o dever de invalidar os seus próprios atos caso inobservados os critérios editalícios para a escolha da proposta mais vantajosa. 6. Recurso desprovido. (TJ-ES - AC: 6070010027 ES 6070010027, Relator: SAMUEL MEIRA BRASIL JUNIOR, Data de Julgamento: 22/07/2008, SEGUNDA CÂMARA CÍVEL, Data de Publicação: 18/08/2008)

BRASIL. Tribunal de Justiça de Santa Catarina. Habeas data - natureza jurídica - delegado de polícia foto em álbum de suspeitos de crimes - requerimento de informações - recusa por omissão. Segundo o art. $8^{\circ}, \S 1^{\circ}$, inciso I, da Lei n. 9.053/97, é requisito da ação de habeas data a inadmissão por parte da autoridade coatora em prestar as informações solicitadas. In casu, o togado a quo extinguiu o processo sem julgamento do mérito, por falta de interesse de agir, considerando que o requerimento administrativo anexado não constituiu prova suficiente à recusa, pois não fora protocolado. NORMA CONSTITUCIONAL - INTERPRETAC̃̃̃O TÓPICA - CONCRETIZAČ̃̃O. No procesSO de concretização da norma, o juiz deve partir do problema, considerando também as normas, mas com o desprendimento suficiente para atingir o objetivo principal que é a efetividade do direito que se busca garantir. Partindo de pontos-de-vista varíáveis, ou seja, dos topoi, segundo os quais se ponderam os prós e os contras das opiniões para a conducão do que é verdadeiro, busca-se o resultado mais justo para o litígio. EXTINÇÃO SEM ANÁLISE DO MÉRITO - PROCESSO EM CONDIÇÕES DE JULGAMENTO. Segundo o art. 515, $\S 3^{\circ}$, do CPC, é permitido ao tribunal ad quem o julgamento imediato da lide, quando a causa versar sobre questão exclusivamente de direito. (TJ-SC - AC: 64802 SC 2004.006480-2, Relator: Volnei Carlin, Data de Julgamento: 21/10/2004, Primeira Câmara de Direito Público, Data de Publicação: Apelação cível n. 04.006480-2, de Joinville).

BUENO, Cássio Scarpinella. Novo Código de Processo Civil Anotado. São Paulo: Saraiva, 2015. 
CÂMARA, Alexandre Freitas. O novo processo civil brasileiro 2a ed. São Paulo, Atlas, 2016.

CANARIS, Claus-Wilhelm. Pensamento sistemático e conceito de sistema na ciência do Direito. $3^{\text {a }}$ ed. Lisboa: Fundação Calouste Gulbekian, 2002.

HART, Herbert L. A. O conceito de Direito. 2. ed. Lisboa: Fundação Calouste Gulbenkian, 1994.

HAYEK, Friedrich August von. Direito, legislação e liberdade: uma nova formulação dos princípios liberais de justiça e economia política. São Paulo: Visão, 1985.

KELSEN, Hans. Teoria pura do Direito. 6. ed. São Paulo: Martins Fontes, 1998.

KRELL, Andreas Joachim. Para além do fornecimento de medicamentos para indivíduos: O exercício da cidadania jurídica como resposta à falta de efetivação dos direitos sociais: em defesa de um ativismo judicial moderado no controle de políticas públicas. In: FEITOSA, Enorque; FREITAS, Lorena; CATÃO, Adrualdo, RABENHORST, Eduardo (org.). O Judiciário e o Discurso dos Direitos Humanos: volume 2. Recife: Ed. Universitária da UFPE, 2012.

KRELL, Andreas Joachim; KRELL, Olga Jubert Gouveia. A Importância do Raciocínio RetóricoTópico para uma melhor Compreensão da Dinâmica da Argumentação Jurídica na Contemporaneidade. In: Quaestio Iuris. Vol. 09, n.01. Rio de Janeiro, 2016.

LORENZETTI, Ricardo Luis. Teoria da decisão judicial: fundamentos de Direito. Trad. Bruno Miragem. São Paulo: RT, 2009.

LUIZ, Fernando Vieira. Teoria da decisão Judicial: dos paradigmas de Ricardo Lorenzetti à resposta adequada à Constituição de Lenio Streck. Porto Alegre: Livraria do Advogado, 2013.

LUÑO, Antonio Enrique Pérez. Perspectivas e tendências atuais do Estado constitucional. Trad. José Luiz Bolzan de Morais, Valéria Ribas do Nascimento. Porto Alegre: Libraria do Advogado, 2012.

MARINONI, Luiz Guilherme. Precedentes obrigatórios. $4^{\mathrm{a}}$ ed. São Paulo: Editora Revista dos Tribunais, 2016.

NOGUEIRA, Pedro Henrique. Negócios jurídicos processuais. Salvador: Juspodivm, 2016.

POSNER, Richard A. Para além do Direito. Trad. Evandro Ferreira e Silva. São Paulo: Martins Fontes, 2009.

RODRIGUEZ, José Rodrigo. Como decidem as cortes?: para uma crítica do direito (brasileiro). Rio de Janeiro: Editora FGV, 2013.

STRECK, Lenio. Lições de críticas hermenêutica do Direito. 2. ed. Porto Alegre: Livraria do Advogado, 2016.

Hermenêutica jurídica e(m) crise: uma exploração hermenêutica da construção do Direito. 11. ed. Porto Alegre: Livraria do Advogado, 2014.

SUNSTEIN, Cass R.; SCHKADE; David; ELLMAN, Lisa M; SAWICKI, Andres. Are Judges Political? an empirical analysis of the federal judiciary. Washington, D.C.: Brooking Institution Press, 2006. 
TARUFFO, Michele. Verdade Negociada. In: Revista Eletrônica de Direito Processual - REDP. Rio de Janeiro, 2014, Volume XIII, n. 13. Disponível em: <http://www.redp.com.br〉. Acesso em 14 set. de 2016.

VIEHWEG, Theodor. Tópica e Jurisprudência. Trad. Tércio Sampaio Ferraz Jr. Brasília: UnB, 1979.

VIGO, Rodolfo Luis. Interpretação jurídica: do modelo juspositivista-legalista do século XIX às nossas perspectivas. 2. ed. Trad. Suzana Elena Dalle Mura. São Paulo: Revista dos Tribunais, 2010.

WALDRON, Jeremy. The Core of the Case Against Judicial Review. Yale: The Yale Law Journal, Apr 2006, 115, 6, p. 1406. 